\title{
Faktor-faktor Determinan yang Mempengaruhi Subjective Well-Being Remaja Penyandang Disabilitas
}

\author{
Fairuz Hasyifah Witjaksono', Abdul Muhid ${ }^{1}$ \\ ${ }^{1}$ Fakultas Psikologi dan Kesehatan UIN Sunan Ampel Surabaya
}

DOI: http://doi.org/10.29080/jpp.v12i2.639

\begin{abstract}
Physical limitations in persons with disabilities make their subjective wellbeing low. This quantitative study aims to determine whether self-adjustment, selfesteem and social support affect the subjective well-being of adolescents with physical disabilities. Data collection tools used are self-adjustment scale, self-esteem scale, social support scale and subjective well-being scale. The research subjects were 60 adolescents with physical disabilities from a total population of 60. Using the quantitative correlation method, the data analysis used was the Structural Equation Model (SEM). The results showed that the variables of self-adjustment, self-esteem, and social support had an effect on subjective well-being.
\end{abstract}

Kata kunci : self-adjustment, self-esteem, social support, subjective well-being

\begin{abstract}
Abstrak : Keterbatasan fisik pada penyandang disabilitas membuat subjective well-being mereka rendah. Penelitian kuantitatif ini bertujuan untuk mengetahui apakah penyesuaian diri, harga diri dan dukungan sosial berpengaruh terhadap subjective well-being remaja penyandang disabilitas fisik. Alat pengumpulan data yang digunakan adalah skala penyesuaian diri, skala harga diri, skala dukungan sosial dan skala subjective well-being. Subjek penelitian berjumlah 60 remaja penyandang disabilitas fisik dari total populasi 60 . Menggunakan metode kuantitatif korelasional, analisis data yang digunakan adalah Structural Equation Model (SEM). Hasil Penelitian menunjukkan variabel penyesuaian diri, harga diri, dan dukungan sosial berpengaruh terhadap subjective well-being.
\end{abstract}

Kata kunci : penyesuaian diri, harga diri, dukungan sosial, subjective well-being

\section{Pendahuluan}

Subjective well-being berkaitan dengan penilaian individu terhadap pengalaman hidup yang didasari pada aspek kognitif dan afektif (Diener, 2005). Apabila individu memiliki kesejahteraan psikologis yang baik maka mereka dapat merasakan bahagia secara afeksi dan merasa puas dengan kemampuan kognitif yang dimilikinya. Kepribadian, demografis, hubungan sosial dan dukungan sosial merupakan sejumlah faktor yang mempengaruhi subjective well-being. Seorang Individu dengan subjective well-being tinggi akan lebih mudah untuk menjalin hubungan sosial yang baik (Larasati, 2017).

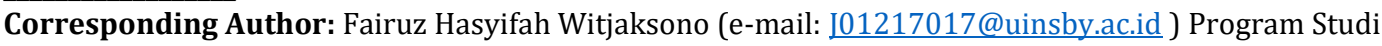
Psikologi Fakultas Psikologi dan Kesehatan UIN Sunan Ampel Surabaya, Jl. A. Yani 117 Surabaya Jawa Timur, Indonesia 60237 
Dalam beberapa kasus tertentu subjective well-being sering dijadikan indikator untuk mengukur tingkat penyesuaian diri pada individu dengan kondisi disabilitas.

Banyak penelitian mengungkapkan bahwa subjective well-being merupakan indikator menarik untuk dijadikan bahan penelitian dalam bidang rehabilitasi. Subjective well-being merupakan suatu hal yang penting untuk dimiliki oleh penyandang disabilitas fisik karena hal tersebut dapat memberikan pengaruh terhadap perkembangan hidupnya di masa yang akan datangRemaja penyandang disabilitas fisik merupakan salah satu kelompok yang terbilang memiliki tingkat subjective well-being rendah. Penelitian Aminzadeh dkk (2018) menunjukkan rendahnya subjective well-being yang dialami karena keterbatasan fisik yang dimilikinya. Remaja penyandang disabilitas perlu mendapatkan dukungan dengan memberikan kebahagiaan di dalam lingkungan mereka sehingga dapat meningkatkan subjective well-being mereka (Carolina, 2006).

Berdasarkan fakta empiris faktor yang dapat mempengaruhi tingkat subjective well-being adalah penyesuaian diri (Kartono, 2008). Fatimah (2008) menggambarkan penyesuaian diri sebagai proses mencapai keseimbangan diri berdasarkan lingkungan. Penyesuaian diri memiliki konstribusi positif terhadap subjective well-being pada remaja penyandang disabilitas fisik (Al-Kharimah, 2015).

Selain itu faktor pendukung selanjutnya yang dapat mempengaruhi subjective well-being pada remaja penyandang disabilitas fisik adalah harga diri. Harga diri merupakan suatu penilaian positif ataupun negatif untuk diri sendiri dalam memandang dirinya mampu dan berharga (Myers, 2005). Remaja penyandang disabilitas fisik dengan harga diri tinggi menganggap bahwa penampilan fisik bukanlah tolak ukur dalam mempresepsikan diri. Penelitian Fajar (2020) menunjukkan dukungan sosial dan harga diri berpengaruh terhadap kesejahteraan subjektif penyandang disabilitas fisik. Penelitian Ji dkk (2019) juga menunjukkan bahwa harga diri secara signifikan memberikan pengaruh terhadap subjective well-being

Faktor yang juga dapat mempengaruhi tinggi rendahnya subjective well-being remaja penyandang disabilitas fisik adakah dukungan sosial. Chaplin (2005) mengemukakan bahwa dukungan sosial merupakan pengadaan suatu hal untuk memberikan wadah pertolongan bagi orang lain berupa bantuan dan dorongan ataupun motivasi. Dukungan sosial dari lingkungan sekitar sangat dibutuhkan untuk dapat memunculkan perasaan positif dalam kehidupan mereka. Dukungan sosial positif yang diberikan secara terus menerus oleh masyarakat sekitar maupun kerabat terdekat dapat mempengaruhi subjective well-being remaja penyandang disabilitas fisik (Nugroho, 2011).

Penelitian Larasati (2017) juga menunjukkan dukungan sosial dan optimisme berhubungan dengan subjective well-being pada remaja tuna daksa. Itzick dkk (2017) melihat persepsi dukungan sosial merupakan komponen penting dalam subjective well-being individu dengan disabilitas fisik. Syarah (2019) juga mengungkapkan bahwa terdapat hubungan positif dan signifikan antara social support dengan subjective wellbeing pada siswa penyandang disabilitas fisik.

Remaja penyandang disabilitas fisik tidak hanya memiliki banyak permasalahan dalam dirinya tetapi juga pengaruh lingkungan sekitar yang membuat mereka memiliki perasaan negatif dan perilaku tidak bahagia dalam hidupnya. Sudah banyak penelitian tentang subjective well-being remaja penyandang disabilitas fisik dengan berbagai variabel psikologis. Namun penelitian ini melihat subjective well-being remaja penyandang disabilitas fisik dari variabel penyesuaian diri, harga diri dan dukungan sosial. Jumlah variabel psikologis yang dibahas dengan konsep yang berbeda diharapkan dapat menghasilkan sudut pandang berbeda dari penelitian sebelumnya. Selain itu subjek penelitian ini menggunakan subjek remaja dengan rentan usia 18 hingga 24 tahun dan belum menikah. 


\section{Metode Penelitian}

Penelitian ini menggunakan metode penelitian kuantitatif dengan mengambil semua populasi yang ada. Populasi dalam penelitian ini adalah seluruh remaja penyandang disabilitas fisik di UPT Rehabilitasi Sosial Bina Daksa yang berlokasi di Kota Pasuruan Jawa Timur. Pengambilan data dalam penelitian ini menggunakan teknik Total Sampling dengan jumlah 60 remaja berusia 18 hingga 24 tahun.

Instrument pengumpulan data penelitian menggunakan skala subjective well-being, skala penyesuaian diri, skala harga diri dan skala dukungan sosial. Seluruh skala dibuat oleh peneliti sendiri. Analisis data yang digunakan adalah Structural Equational Modelling (SEM) dengan aplikasi SmartPLS v 3.3.3.

\section{Hasil Penelitian}

Data deskriptif menunjukkan jumlah responden laki-laki lebih banyak (55\%) dibandingkan perempuan (45\%). Berdasarkan kriteria usia presentase terbanyak ada pada responden yang berusia 20 tahun (25\%), sedangkan paling sedikit ada pada kelompok usia 24 tahun (5\%.) Jumlah responden juga dikelompokkan berdasarkan jenis disabilitas fisik dimana kategori ringan sebanyak $90 \%$ dan kategori sedang sebanyak $10 \%$. Tidak ada kriteria berat dalam penelitian ini.

Tabel 1

Data Demografi Sampel Penelitian ( $\mathrm{N}=60)$

\begin{tabular}{|c|c|c|}
\hline Karakteristik Responden & Frekuensi & Presentase \\
\hline \multicolumn{3}{|l|}{ Jenis kelamin : } \\
\hline Laki-laki & 33 & $55 \%$ \\
\hline Perempuan & 27 & $45 \%$ \\
\hline Total & 60 & $100 \%$ \\
\hline \multicolumn{3}{|l|}{ Usia } \\
\hline 18 tahun & 6 & $10 \%$ \\
\hline 19 tahun & 9 & $15 \%$ \\
\hline 20 tahun & 15 & $25 \%$ \\
\hline 21 tahun & 12 & $20 \%$ \\
\hline 22 tahun & 6 & $10 \%$ \\
\hline 23 tahun & 9 & $15 \%$ \\
\hline 24 tahun & 3 & $5 \%$ \\
\hline $\begin{array}{r}\text { Total } \\
\end{array}$ & 60 & $100 \%$ \\
\hline \multicolumn{3}{|l|}{ Jenis Disabilitas } \\
\hline Ringan & 54 & $90 \%$ \\
\hline Sedang & 6 & $10 \%$ \\
\hline Berat & 0 & $0 \%$ \\
\hline Total & 60 & $100 \%$ \\
\hline
\end{tabular}

Sebelum melakukan analisa data, terlebih dahulu dilakukan uji validitas dan reliabilitas. Nilai korelasi semua item pertanyaan pada kuesioner untuk keseluruhan indikator dan item bernilai di atas 0,70. Namun terdapat satu item yang memiliki nilai dibawah 0,70 yaitu sebesar 0,684 maka dapat dikatakan bahwa item dinilai cukup (Chin, 1998 \& Ghozali, 2006). Dengan demikian dapat disimpulkan bahwa seluruh item telah memenuhi syarat validitas. Adapun nilai cronbach alpha variabel penelitian harga diri dan dukungan sosial bernilai di atas 0,70 sedangkan penyesuaian iri dan subjective well-being bernilai dibawah 0,70 yang artinya adalah cukup. Dengan demikian dapat disimpulkan bahwa instrumen telah memenuhi persyaratan reliabel.

\section{Model Structural}

Tabel 3 disajikan hasil estimasi R-square dengan menggunakan SmartPLS. Model struktural menyajikan hubungan antar variabel penelitian. Model struktural dievaluasi 
dengan menggunakan R-square untuk konstruk dependen uji t serta signifikansi dari koefisien parameter jalur. Penilaian model dengan PLS dimulai dengan melihat R-square, semakin tinggi nilai R2 berarti semakin baik model prediksi dari model penelitian yang diajukan (Jogiyanto, 2011 \& Abdillah, 2009). Nilai R-square untuk variabel Y diperoleh sebesar 0,657. Hasil ini menunjukkan bahwa 65,70\% variabel Penyesuaian Diri, Harga Diri Dan Dukungan Sosial berpengaruh terhadap variabel Subjective well-being.

Tabel 3

Composite Reliability, Cronbach's Alpha dan R Square

\begin{tabular}{cccc}
\hline Variabel & Cronbach's Alpha & Composite Reliability & R Square \\
\hline Penyesuaian Diri (X1) & 0,648 & 0,850 & 0 \\
\hline Harga Diri (X2) & 0,869 & 0,911 & 0 \\
\hline Dukungan Sosial (X3) & 0,799 & 0,862 & 0 \\
\hline Subjective well-being (Y) & 0,680 & 0,862 & 0,657 \\
\hline
\end{tabular}

\section{Pengujian Hipotesis}

Tabel 4 disajikan hasil pengujian model struktural langsung. Pengujian hipotesis dilakukan dengan melihat path coefficient yang menunjukkan parameter dan nilai tstatistics. Skor koefisien path atau inner model yang ditunjukkan oleh nilai T-statistik harus di atas 1,96 untuk hipotesis dua ekor (two-tailed) dan P Values dibawah 0,05. Hasil pengujian model secara langsung sebagai berikut.

Tabel 4

Path Coefficient - Bootstrap

\begin{tabular}{cccccc}
\hline Konstruk & $\begin{array}{c}\text { Original } \\
\text { sample } \\
(\mathbf{O})\end{array}$ & $\begin{array}{c}\text { Sample } \\
\text { mean (M) }\end{array}$ & $\begin{array}{c}\text { Standard } \\
\text { deviation } \\
\text { (STDEV) }\end{array}$ & $\begin{array}{c}\text { T Statistic } \\
(\text { (OO/STDEVI) }\end{array}$ & P Values \\
\hline $\begin{array}{c}\text { Penyesuaian Diri } \leftarrow \\
\text { Subjective well-being }\end{array}$ & 0,374 & 0,360 & 0,100 & 3,734 & 0,000 \\
\hline $\begin{array}{c}\text { Harga Diri } \leftarrow \text { Subjective } \\
\text { well-being }\end{array}$ & 0,529 & 0,518 & 0,090 & 5,908 & 0,000 \\
\hline $\begin{array}{c}\text { Dukungan Sosial } \leftarrow \\
\text { Subjective well-being }\end{array}$ & 0,239 & 0,236 & 0,107 & 2,235 & 0,026 \\
\hline
\end{tabular}

\section{Pembahasan}

Hasil penelitian menunjukkan bahwa penyesuaian diri memiliki pengaruh yang positif dan signifikan terhadap subjective well-being. Penjelasan tersebut sesuai dengan penelitian Al-Kharimah (2015) yang melihat pengaruh signifikan variabel penyesuaian diri terhadap subjective well-being. Diener (2002) juga mmenjelaskan bahwa subjective wel-being dapat dipengaruhi oleh beberapa faktor dan salah satunya adalah penyesuaian diri. Penyesuaian diri sangat dibutuhkan sebagai acuan untuk mengubah perilaku individu agar tercipta hubungan baik dengan lingkungannya. Remaja penyandang disabilitas fisik dengan penyesuaian diri yang tinggi mampu beradaptasi dengan situasi di lingkungannya. Namun apabila remaja penyandang disabilitas fisik memiliki penyesuaian diri yang rendah maka mereka tidak akan mampu bahagia di lingkungannya. Mereka mudah memiliki perasaan terkucilkan dari lingkungan dan tidak memiliki keyakinan positif atas dirinya.

Hasil penelitian berikutnya adalah harga diri memiliki pengaruh yang positif dan signifikan terhadap subjective well-being. Penjelasan tersebut diperkuat oleh penelitian Ji dkk(2019) yang menunjukkan bahwa harga diri memberikan pengaruh signifikan terhadap subjective well-being pada penyandang disabilitas fisik. Harga diri merupakan aspek sosial yang dapat menentukan keberhasilan individu dalam berinteraksi dengan lingkungan sosial. Hal tersebut dapat menciptakan perasaan aman dan mudah menyesuaikan diri dengan lingkungannya (Knapp dalam Widodo, 2013). 
Remaja penyandang disabilitas fisik tergolong individu yang memiliki harga diri rendah. Ketika harga diri tinggi maka mereka dapat memiliki penerimaan atas dirinya tanpa syarat. Namun mereka dengan harga diri rendah merasa tidak ada hal baik yang mampu membantu diri dan mampu berguna bagi lingkungannya (Struart, 2007).

Hasil selanjutnya adalah terdapat pengaruh dukungan sosial terhadap subjective well-being terbukti. Penelitian Syarah (2019) jug amenunjukkan hasil yang sama dimana social support berpengaruh terhadap terbentunya subjective well-being. Selain itu Fajar (2020) dalam penelitiannya juga melihat hubungan yang signifikan antara dukungan sosial terhadap subjective well-being penyandang disabilitas fisik. Selanjutnya penelitian Larasati (2017) dan Itzick dkk (2017) juga menjelaskan hubungan yang signifikan antara dukungan sosial dengan subjective well-being penyandang disabilitas fisik.

Berikutnya adalah variable dukungan sosial yang juga menunjukkan adanya hubungan postif dengan subjective well-being dalam penelitian ini. Dukungan sosial tidak hanya memberikan bantuan namun yang paling penting adalah bagaimana bentuk persepsi penerima terhadap maksud dari bantuan tersebut (Kumalasari \& Ahyani, 2012). Dalam meningkatkan subjective well-being, remaja penyandang disabilitas fisik menganggap bahwa dukungan sosial merupakan suatu hal yang tidak dapat diabaikan. Selain itu hubungan interpersonal mengandung dukungan perasaan emosi, penilaian, perhatian dan bantuan instrumental. Remaja penyandang disabilitas fisik dengan dukungan sosial yang tinggi akan memberikan manfaat dalam mengembangkan kepribadian yang sehat dan membuatnya mampu untuk menciptakan kepribadian positif. Sebaliknya apabila remaja penyandang disabilitas fisik tidak memiliki dukungan sosial yang cukup maka stres, kecemasan dan berbagai bentuk tekanan lainnya akan muncul.

Adapun hasil penelitian terakhir adalah adanya pngaruh penyesuaian diri, harga diri dan dukungan sosial terhadap subjective well-being. Nilai 65,7 \% menunjukkan ketiga variable berkontribusi terhadap terbentuknya subjective well-being. Diener (2002). Menjelaskan ada banyak faktor yang dapat mempengaruhi subjective well-being antara lain adalah harga diri, tujuan hidup, kepribadian hubungan sosial dan faktor psikologis lainnya. Individu yang mampu mencapai tujuan hidupnya merupakan individu yang memiliki perasaan bahagia sebagaimana perasaan yang sejahtera dan puas dengan apa yang dirasakan dalam kehidupannya. Individu dengan subjective well-being yang tinggi mampu mendapatkan rasa bahagia (Kasebir \& Diener, 2008).

\section{Simpulan dan Saran}

Hasil penelitian ini menunjukkan pengaruh positif dan signifikan dari penyesuaian diri terhadap subjective well-being remaja penyandang fisabilitas fisik. Semakin tinggi penyesuaian diri maka semakin baik subjective well-being yang dimiliki. Selain itu harga diri yang dimiliki juga berpengaruh terhadap subjective well-being. Dukungan Sosial yang diterima juga berpengaruh pada subjective well-being dimana semakin tinggi dukungan sosial semakin tinggi subjective well-being mereka. Hasi terakhir adalah adanya pengaruh dari tiga variable yang digunakan yaitu penyesuaian diri, harga diri dan dukungan sosial terhadap subjective well-being remaja penyandang Disabilitas Fisik.

Kondisi remaja penyandang disabilitas fisik yang berada di UPT Rehabilitasi membutuhkan banyak bantuan untuk dapat terus meningkatkan subjective well-being mereka. Dukungan dari keluarga dan lingkungan sekitar sangat dibutuhkan agar mereka bahagia dalam menjalani kehidupannya walaupun dengan keterbatasan fisik. Sejumlah item yang digunakan dalam penelitian ini masing ada yang sulit dipahami oleh responden da itu bisa mnejadi bahan bagi penekitian selanjutnya.data demografi lainnya bisa mnajdi bahan penelitian yang juga lebih fokus dengan metod penelitian yang berbeda sehinga dapat terlihat lebih personal dinamika subjective well-being yang dimiliki responden. 


\section{Daftar Pustaka}

Al-Kharimah, N. F. (2015). Hubungan Antara Penyesuaian Diri Dan Harga Diri Dengan Subjective well-being. Doctoral dissertation, Universitas Muhammadiyah Surakarta.

Aminzadeh., dkk. (2018). Self Compasion Dan Subjective well-being Remaja Tuna Daksa. Jurnal ilmiah psikologi, 6 (2).

Carolina. (2006). Self-Esteem Pada Penyandang Tuna Daksa. Jurnal Wacana, 5 (1).

Chaplin. (2004). Hubungan Antara Penyesuaian Diri Dan Harga Diri Dengan Subjective well-being. Doctoral dissertation, Universitas Muhammadiyah Surakarta.

Diener, E., Lucas, R. E., \& Oishi, S. (2005). Subjective well-being: The science of happiness and life satisfaction. In C. R. Snyder \& S. J. Lopez (Eds.), Handbook of positive psychology (2nd ed.), (pp. 63-73). New York, NY: Oxford University Press.

Fajar, M. (2020). Peran Dukungan Sosial Dan Harga Diri Terhadap Kesejahteraan Subjektif Penyandang Disabilitas Fisik. Doctoral dissertation, Universitas Muhammadiyah Surakarta.

Itzick, M., Kagan. M., \& Tal-Katz. P. (2017). Perceived social support as a moderator between perceived discrimination and subjective well-being among people with physical disabilities in Israel. Disability and Rehabilitation, 40 (18), 2208-2216.

Ji, Yinyin., et al. (2019). Self-Esteem Mediates the Relationships Between Social Support, Subjective Well-Being, and Perceived Discrimination in Chinese People With Physical Disability. Frontries in Psychology, Doi: 10.3389/fpsyg.2019.02230.

Kartono. (2008). Hubungan Kemandirian Dengan Penyesuaian Diri Pada Santri Baru Pondok Pesantren Diniyyah Putri Lampung. Skripsi, UIN Raden Intan Lampung.

Larasati, I. (2017). Hubungan Antara Dukungan Sosial Dan Optimisme Dengan Subjective well-being pada remaja tuna daksa di BBRSBD PROF. DR. Soeharso Surakarta. Skripsi, Universitas Sebelas Maret Surakarta.

Syarah, F. S. (2019). Hubungan Social Support Dengan Subjective well-being Pada Siswa Penyandang Disabilitas Di Banda Aceh. Skripsi, Universitas Islam negeri AR-Raniry Banda Aceh. 